\title{
A METHOD OF SECTIONING ASPIRATED BONE-MARROW
}

\author{
BY \\ K. RAMAN \\ From the Department of Pathology (Haematology), Postgraduate Medical School, London
}

(RECEIVED FOR PUBLICATION DECEMBER 3, 1954)

\begin{abstract}
A technique for preparing histological sections of aspirated bone-marrow to be satisfactory should fulfil the following conditions: it should be simple and easy to perform; it should give a good concentration of marrow particles without much admixture with peripheral blood; it should produce very little lysis of the blood cells ; and it should give good fixation of the tissue so that sections can be stained by Romanowsky dyes as well as by routine stains and nuclear details can be easily discerned. The technique described below is believed to satisfy these conditions and to have advantages over various methods so far described.
\end{abstract}

\section{Other Authors' Methods}

Mertens (1945) collected the marrow in a dry syringe and fixed the resulting coagulum in Zenker's solution. The sections contained marrow particles but also a large amount of peripheral blood.

White, Baker, and Griffin (1946) fixed the aspirated material in a mixture of nine parts of absolute methanol and one part of neutral formalin $(40 \%)$. This method, although giving excellent fixation, failed to concentrate the fragments and also lysed the red cells.

Attempts at exclusion of peripheral blood were made by Schleicher (1947), Berman and Axelrod (1947), and Cappell, Hutchison, and Harvey Smith (1947). Schleicher's method consisted in picking up the gross fragments after illuminating the marrow aspirate from below, the smaller fragments being visualized after dilution with the fixative. This method is tedious and time consuming.

Berman and Axelrod (1947) gathered the fragments on a glass slide in a drop of topical thrombin solution, to which heparinized plasma was added, and the resulting coagulum was fixed. It was possible to rid the fragments of a large amount of the contaminating blood, but the concentration was not adequate.
These two methods were improved on by Cappell and his colleagues (1947) and by Hutchison (1953), who collected the marrow in large volumes of fixative and washed away the excess blood with larger volumes of water after fixation. The former used Zenker's solution minus acetic acid as fixative; the latter used a mixture of sodium sulphate, glacial acetic acid, formalin, and water. These methods, although they are elaborate and time consuming, achieved a good concentration of marrow particles. Lubitz, Greenwalt, and Dessel (1952) and Moomaw and Alt (1954) collected the marrow aspirate on unglazed filter paper and fixed the resulting clot containing the marrow

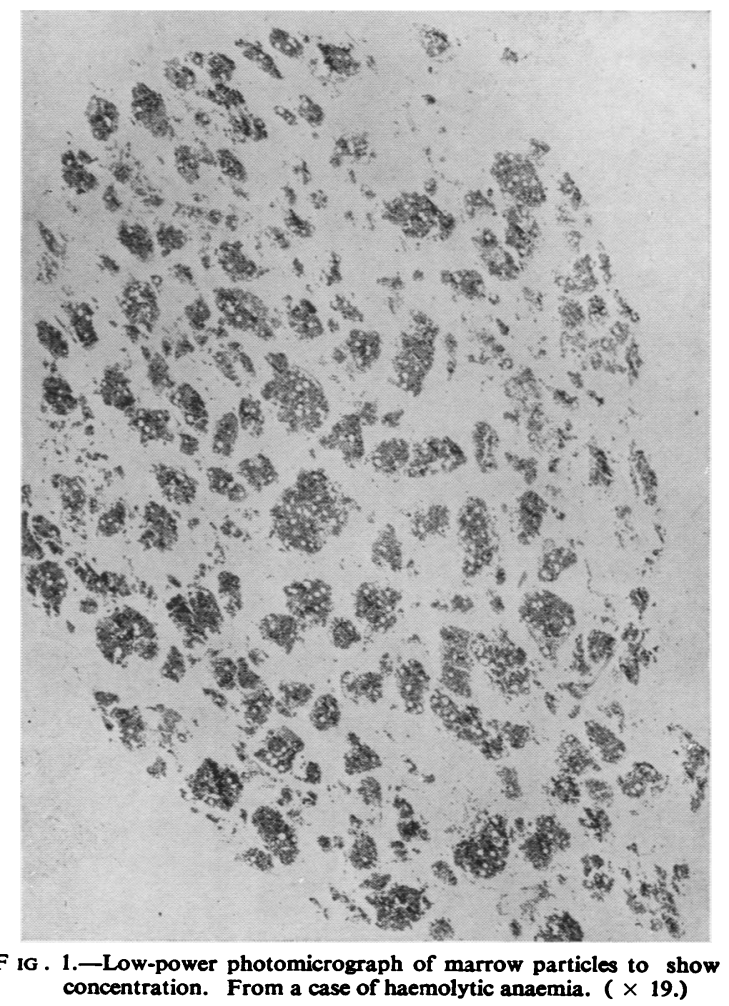


fragments in Zenker's solution. However, in neither method was it possible to exclude blood from the marrow particles nor could a good concentration be obtained.

\section{Method}

The method now described gives a good concentration without much admixture with blood, and produces very little lysis of the red cells (Fig. 1). Fixation of the tissue and nuclear and cytoplasmic staining are satisfactory (Fig. 2).

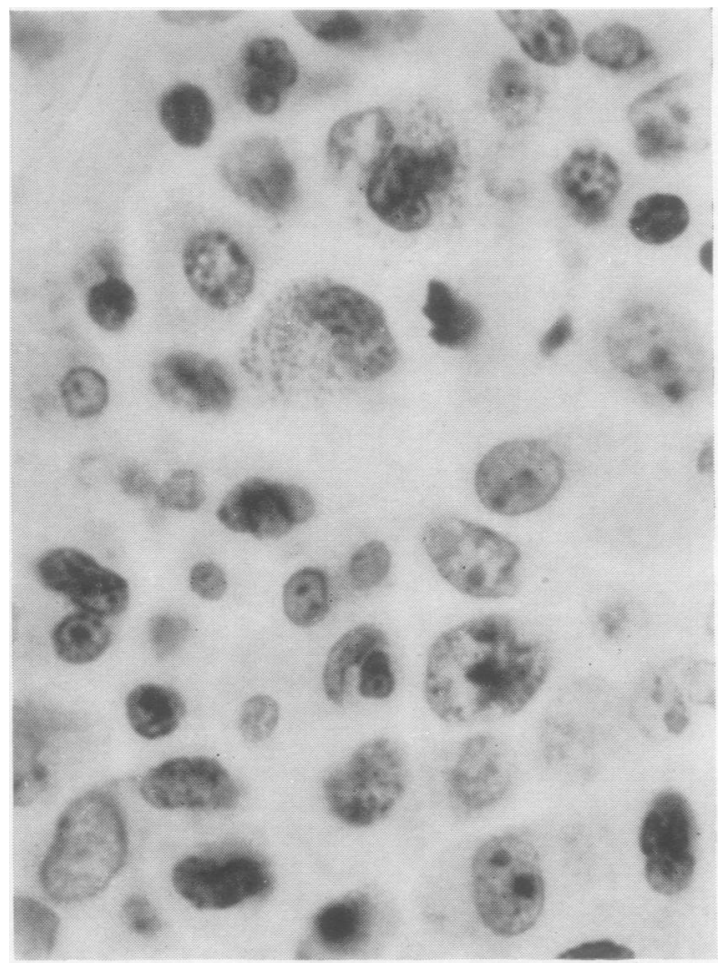

FIG. 2.-High-power photomicrograph of marrow particles. From a case of pernicious anaemia. $(\times 1,150$.

Fixative.-This consists of a mixture of equal parts of $15 \%$ formalin in saline and absolute ethanol. This solution has a specific gravity of about 0.930 , i.e., almost exactly that of human fat-0.92 to 0.94 (Behnke, 1945). When the marrow aspirate is added to the fixative the blood remains in suspension and the coarse marrow fragments rapidly settle down to the bottom of the container; even fatty marrow settles down in a few seconds.
Procedure.-Marrow aspirate, $0.25 \mathrm{ml}$., is added te $20 \mathrm{ml}$. of the fixative in a screw-capped bottle an 4 thoroughly mixed. It is then allowed to fix overnigh?

In the morning the sediment is resuspended bo gentle shaking and the coarser fragments are pickef up with a glass pipette after they have settled to th\& bottom of the bottle, which usually takes only a fen seconds. They are then transferred to a centrifuge tube containing $70 \%$ ethanol, which is then close with a rubber bung. The material is subsequentl $\overrightarrow{\underline{v}}$ dehydrated with two changes of absoiute ethanol fog one hour each. The alcohol is then drained off and replaced with a $2.5 \%$ solution of "necol "* in equa parts of absolute ethanol and ether and left ovepo night. This preliminary embedding in " necol " w necessary to hold the fragments together before theap are finally embedded in paraffin wax (White et af 1946).

On the third day the excess " necol" is drained of and replaced with 2-3 ml. of chloroform to harde⿳⺈ the collodion. After 30 seconds the aggregated mass of fragments is displaced by gently warming the tip of the tube over a very weak flame. The mass $\overrightarrow{\square b}$ fragments is then cleared with two changes of benzerf and embedded in paraffin wax.

\section{Summary}

A simple method is described for preparin histological sections of aspirated marrow. gives adequate concentration of marrow fra $\$$ ments with very little lysis of red cells and goo] fixation of tissue.

This work was undertaken during the tenure of $\frac{\text { 采 }}{2}$ Nuffield Foundation Fellowship.

I have to thank Dr. J. V. Dacie and Dr. D. L. Mollo for their guidance. The histological sections weit cut and stained under the direction of $\mathrm{Mr}$. J. $\mathbf{G}$. Griffin; the photomicrographs were taken by $\mathrm{M} / \mathrm{B}$ C. A. P. Graham.

\section{REFERENCES}

Behnke, A. R. (1945). Medicine, 24, 359.

Berman, L., and Axelrod, A. R. (1947). Amer. J. clin. Path., 17, $6 \mathbb{P}$

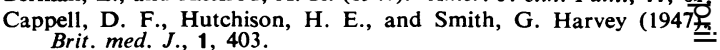

Hutchison, H. E. (1953), Blood 8, 236.

Lubitz, J. M., Greenwalt, T. J., and Dessel, B. (1952). Amer. J. clin. Path., 22, 291.

Mertens, E. (1945). Amer. J. med. Sci., $210,630$.

Moomaw, D. R., and Alt, H. L. (1954). Amer. J. clin. Path., 24, 9200

Schleicher, E. M. (1947). Ibid., 17, 909.

White, J. C., Baker, J. R., and Griffin, J. G. (1946). J. Path. Bact. 58, 155 .

- Necol is obtainable from B.D.H. and sold as Necol Collodio Solution 301-261 (356/A9). 